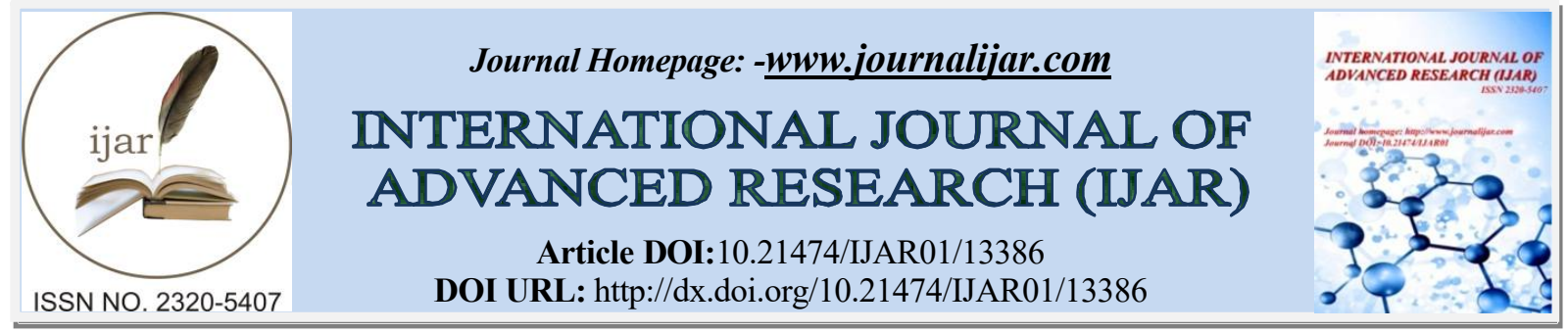

RESEARCH ARTICLE

\title{
PREVALENCE OF PLACENTAL INFECTION WITH PLASMODIUM FALCIPARUM DETECTED BY POLYMERASE CHAIN REACTION AND ASSOCIATED RISK FACTORS IN WOMEN AFTER DELIVERED OUAGADOUGOU (BURKINA FASO)
}

Sawadogo Haffsatou ${ }^{1}$, Zida Adama ${ }^{2,4}$, Zongo Cheikna ${ }^{1}$, Soulama Issiaka ${ }^{8}$, Sawadogo Patindoilba Marcel ${ }^{2,4}$, Guiguemde Kiswendsida Thierry ${ }^{1,7}$, Sermé Sindie Samuel ${ }^{6}$, Sangare Ibrahim ${ }^{5}$, Sangare Lassana ${ }^{2,3}$, Traore Yves $^{4}$, Ouedraogo-Traore Rasmata ${ }^{4,7}$, Guiguememde T. Rober ${ }^{2,4}$ and Savadogo $\mathrm{Aly}^{1}$

1. Laboratoire de Biochimie et Immunologie Appliquées (LABIA), Université Joseph KI-ZERBO, 03 BP 7021 Ouagadougou 03, Burkina Faso.

2. Service de Parasitologie-Mycologie, Centre Hospitalier Universitaire Yalgado Ouédraogo (CHU-YO),03 BP 7022 Ouagadougou 03, Burkina Faso.

3. Service de Bactériologie-Virologie, Centre Hospitalier Universitaire Yalgado Ouédraogo, 03 BP 7022 Ouagadougou 03, Burkina Faso.

4. Unité de Formation et de Recherche en Sciences de la Santé, Université Joseph KI-ZERBO, BP 7021 Ouagadougou 03, Burkina Faso.

5. Institut Supérieur des Sciences de la Santé (INSSA), Université Nazi Boni, 01BP1091 Bobo-Dioulasso 01Burkina Faso.

6. Centre National de Recherche et de la Formation sur le Paludisme (CNRFP), Institut National de Sante Publique, 01 BP 2208, Ouagadougou, Burkina Faso.

7. Centre Hospitalier Universitaire Charles De Gaulles (CHUP-CDG), 01 BP 1198 Ouagadougou 01, Burkina Faso.

8. Institut de Recherche en Sciences de la Santé (IRSS),03 BP 7192 Ouagadougou 03, Burkina Faso.

\section{Manuscript Info}

\section{Manuscript History}

Received: 10 July 2021

Final Accepted: 13 August 2021

Published: September 2021

Key words: -

Prevalence, Risk Factor, Plasmodium Falciparum, Pregnant Women, Placenta, Ouagadougou

\begin{abstract}
Background:Malaria is known to have a negative impact on pregnant women and their foetuses. This infection during pregnancy represents a major public health problem in tropical and subtropical regions. The aim of this study was to determine the prevalence and risk factor of Plasmodium falciparum in pregnant women the city of Ouagadougou (Burkina Faso).

Methods:A cross-sectional study was conducted from April 2019 to March 2020 in four health districts within Ouagadougou, capital city. Samples were collected from the placenta from 531 women after delivered Plasmodium falciparum then by PCR.

Results: The prevalence placental malaria with of Plasmodium falciparum was estimated at $7.53 \%$. The status of unemployment and/ or the status of residence around the city of Ouagadougou represent risk of malaria infection.

Conclusion:Malaria in pregnancy is responsible for several complications so emphasis should be placed on communication about malaria control in pregnancy and, the behavior of pregnant women and health workers as well.
\end{abstract}

Copy Right, IJAR, 2021,. All rights reserved. 


\section{Introduction:-}

Malaria is a life-threatening parasite disease transmitted an of infected Anopheles female mosquitoes. According to the World Health Organization (WHO), more than half of world's population was at risk of malaria in 2019 (WHO, 2021). Unfortunately, the vast majority of malaria cases and deaths occur in are from sub-Saharan Africa, where about 30 million pregnant women are highly exposed to the disease each year (Tegegneet al., 2017).

Malaria infection during pregnancy is a major public health, and poses substantial risks to the mother, her fetus and the new-born (Kanbanywanyiet al., 2008). Indeed, it may cause a variety of adverse consequences including maternal anaemia and death, placental accumulation of parasites, low-birth-weight neonates from intrauterine growth retardation, congenital infections and infant mortality with higher rates of miscarriage, intrauterine demises, premature delivery and neonatal death (Felekeet al., 2020).

Burkina Faso is among the ten countries with the highest number of malaria cases and deaths with $3 \%$ of the global cases and deaths and is also among the 20 countries where the prevalence of exposure to malaria infection during pregnancy was more than $30 \%$ while maternal anaemia was over $40 \%$ in 2018 (WHO, 2019).

For the prevention of malarial disease during pregnancy the World Health Organization has recommended since 2004 relevant strategies, such as the administration of intermittent preventive treatment IPT with Sulfadoxine/Pyrimethamine during pregnancy, the use of insecticide-treated bed nets (ITN) by pregnancy women and the effective management of clinical cases to reduce the burden of malaria and improve pregnancy outcome. In Burkina Faso, Intermittent preventive treatment with Sulfadoxine/Pyrimethamine (IPTp-SP) was adopted in 2005, with the objective of giving at least three doses of sulfadoxine-pyrimethamine to women during their pregnancy (Cisséet al., 2017).

Despite the implementation of WHO strategies, the recent studies have shown that an important proportion of pregnant women were infected and had sequestered parasites in their placenta (Cissé et al., 2014; Tionoet al., 2009; Elimeet al., 2019). This situation could be explained par many risks factors such as pregnant women behaviour towards disease prevention. Lack of formal education, attitude health workers, access measures prejudices and resistance of Plasmodium falciparum to antimalarial agents constitute important other factors contributing to the persistence of malaria with its adverse effects (Ouedraogo et al., 2011). This cross-sectional study was performed with the aims to determine by using a PCR detection method the prevalence and risk factors of placental malaria infection in pregnancy women living in Ouagadougou the capital city of Burkina Faso. The study results will help to update on the placental malaria infection in Burkina Faso

\section{Methods:- \\ Study sites}

A cross-sectional study was conducted in the hospital of four health districts of the city of Ouagadougou named, the Boulmiougou district hospital, the Paul VI hospital, the Schiphra hospital and the Noongr-Massom district hospital.

Ouagadougou is the capital of Burkina Faso (lat. $12^{\circ} 22^{\prime} \mathrm{N}$ and long. $1^{\circ} 31^{\prime} \mathrm{W}$ ). Its population is estimated at around 2 684052 inhabitants in 2020. This city is subjected to tropical savanna climate with a rainy season between June and October, a cold and dry season between November and January, and a hot and dry season between February and May. There are three artificial lakes located within the city intended to supply water to the population. Malaria transmission is considered to be high in Ouagadougou.

we sectioned 4 sites that correspond to the major hospitals of the citywhich are the Boulmiougou district hospital located in the district of Boulmiougou, the Paul VI hospital in the district of Sig-Nonghin, the Schiphra hospital and the Noongr-Massom district hospital in the district of Nongr-Massom (Fig 1).

\section{Study population}

The study enrolled all of pregnant women who accepted to participate to the study and signed the written informed consent form. HIV positive pregnant women were excluded. A total of 531 women were enrolled. The study was carried out during on year from April 2019 to march 2020. 


\section{Ethical considerations}

Approval for this study was granted by the National Ethics Committee for Health Research of Burkina Faso (deliberation $\mathrm{N}^{\circ}$ 2019-4-056). The study received administrative approval from the district medical officer, the mayor, and the head of each local health centre where the study took place. Pregnant women were approached when reporting delivery. Only pregnant women volunteer who signed an inform consent form for their participation were enrolled.

\section{Demographic and clinical data capturing}

A structured questionnaire was used to capture demographic and clinical data from the pregnant women participating to the study. Data collected included age, marital status, educational level, occupation, current and previous pregnancies, environmental and living conditions. Information about the use of Intermittent Preventing Treatment (IPT) and Insecticide Treated Nets (ITNs) bare also recorded.

\section{Blood sample collection}

To determine the infection of the placenta by Plasmodium falciparum, blood from the maternal face of placenta, thick and thin films preparation according to WHO protocol (WHO, 2020) and blood spotting on filter paper (Whatman $\mathrm{N}^{\circ}$ 3) for PCR detection (Fig 2).

\section{Malaria diagnosis by microscopic method}

Microscopy, which is the WHO reference method for diagnosing malaria was used.Thick and thin films prepared from blood of the maternal face of placenta of each woman were examined by two laboratory microscopists.First, the dried slides were stained with May Grunwald Giemsa for 15 minutes. They are then rinsed with water and left to dry. The slides were read using the oil immersion objective lens of an optimal microscope at 100X magnification. Plasmodium falciparum parasites were counted parallelly with leukocytes. The counting was stopped when the number of leucocytes reached 200 and the following formula was used to determine the parasite density per microlitre of blood:

$$
P D=\frac{\text { numberofcountedparasites } X 8000}{40}
$$

PD is the parasites density per microlitre of blood 8000 is the average number of leucocytes per microliter of blood.

At least 100 high power fields were examined before a thick smear was declared negative

\section{Detection of Plasmodium falciparum by Polymerase Chain Reaction}

Plasmodium falciparum DNA was extracted from dried blood spots using QIAamp® DNA Mini Kit (250) according to the manufacture's recommendation. Eluted DNA was immediately used in amplification reactions or stored at $20^{\circ} \mathrm{C}$ untilprocessing. The DNA amplification method was described elsewhere by nested polymerase chain. The primers sequences for first (nested) amplificationwere: rPLU5 5-CCT GTT GTT GCC TTA AAC TTC-3 (forward) rPLU6 5-TTA AAA TTG TTG CAG TTA AAA CG-3 (reverse). For the second (nested) amplification were used rFAL1 5-TTA ACC TGG TTT GGG AAA ACC AAA TAT ATT-3 (forward) rFAL2 5-ACA CAA TGA ACT CAA TCA TGA CTA CCC GTC-3 (reverse).

\section{PCR amplification of Plasmodiumfalciparum}

Amplication was performed an on Applied Biosystem 2720 Thermal cycler. It was in $20 \mu 1$ volume containing $1 \mu 1$ of genomic DNA, $2 \mu 1$ of polymerase chain reaction (PCR) buffer $10 \mathrm{X}, 0.5 \mu 1$ of $10 \mu \mathrm{M}$ of each primer, $1.25 \mu 1$ of $\mathrm{mM}$ of dNTP, $0.8 \mu \mathrm{l}$ of $50 \mathrm{mM}$ of $\mathrm{MgCl}_{2}$ and 0.1 of $5 \mathrm{UI}$ Taq polymerase. The system was programmed to $5 \mathrm{~min}$ for initial denaturation at $95^{\circ} \mathrm{C}$, to $1 \mathrm{~min}$ of denaturation at $94^{\circ} \mathrm{C}$ and this was followed by 24 cycles, each consisting of $1 \mathrm{~min}$ of denaturation at $94^{\circ} \mathrm{C}, 2 \mathrm{~min}$ of annealing at $58^{\circ} \mathrm{C}, 2 \mathrm{~min}$ of extension at $72^{\circ} \mathrm{C}$. At the final cycle, an additional 5 min of incubation at $72^{\circ} \mathrm{C}$ was performed to complete the extension. For second amplification the cycle condition outer PCR 30 cycles. The amplified PCR products were either stored at $+4^{\circ} \mathrm{C}$ or analysed immediately by electrophoresis on a agarose gel (Fig 3).

\section{Data interpretation}

Data DNA fragments from the second amplification electrophoresis were assessed and data interpreted as Plasmodium falciparum positive when the size the DNA is about $205 \mathrm{bp}$. 


\section{Statistical analysis}

The data were analysed using $\mathrm{R}$ software. The proportions comparison was made by Chi-Square and normally distributed continuous data by the Student's t-test and ANOVA.

\section{Results:-}

\section{Characteristics of the study population}

A total 531 blood spots samples were obtained. The mean age of the study participants from the four sites was estimated at 26.9 years. About $30.80 \%$ patients were primigravidae, $54.04 \%$ patients lived in Ouagadougou city and $45.63 \%$ were unemployed, of which $53.04 \%$ were married.

\section{Prevalence of placental malaria}

In our study, we obtained a prevalence of placental malaria of $7.53 \%$. This prevalence was only for Plasmodium falciparum.

\section{Factors associated with placental malaria infection}

Several factors are identified to be associated with placental malaria. These different risk factors are summarized inTable 1.

\section{Influence of risk factors on placental malaria prevalence}

The Table 2 represent age, residence place, occupation, gestures, and parity prevalences. It reveals more positive cases in the 18 to 25 years, among parturient living around Ouagadougou city's, those who were without a profession, paucigestures and pauciparous. The difference was statistically significant at the level of place and occupation with $\mathrm{p}$ value of $(\mathrm{P}=0.0046$ and $\mathrm{P}=0.0186)$ respectively. The Table 3 reveals more positive cases in the 18 to 25 years, among parturients living around the city of Ouagadougou, those whose were without a profession, paucigestes and pauciparus. The difference was statistically significant at the level of place of residence and occupation $(\mathrm{P}=0.0046$ and $\mathrm{P}=0.0186)$.

The table below sums up the influence of the location antenatal consultation (ANC) the qualification of the ANC agent on the placental malaria infection (Table 4). There were more positive cases among women who underwent their antenatal consultation (ANC) in the SPHC and by midwives. The difference was statistically significant among women who have had their antenatal consultation witha midwife $(\mathrm{P}=0.0174)$. There was no statistically significant association between placental malaria infection of TPI supervised, using long-acting insecticide-treated mosquito net, start IPT and secondary effects (Fig 4).

\section{Discussion:-}

The present study was designed to determine the prevalence of placental malaria infection and risk factor among delivering women at the main hospitals in Ouagadougou, Burkina Faso. The prevalence observed in our study $7.53 \%$ was lower compared to the prevalence previously reported elsewhere, $19.40 \%$ and $19.50 \%$ in Angola (Valente et al., 2011) and Burkina Faso (Ouedraogo et al., 2012) respectively. The factors responsible for such variations in the placental malaria prevalence were reported to be acquired immunity related to the malaria transmission in the various setting (Omer et al., 2017). This difference may be explained by the fact that parturients in our study received intermittent preventive treatment with Sulfadoxine/Pyrimethamine. Moreover, this prevalence is higher than the previous recorded in a study in Ghana (Stephens et al., 2014).

The risk of the malaria infection was higher in pregnant women aged between 18 and 25 years. This is confirmed by Bianor (Valente et al., 2011) who found that the age was also identified as a risk factor for placental malaria infection.

In addition, women unemployed and who lived around the city of Ouagadougou, performing their prenatal consultation in a health and social promotion centre and by midwife. Therefore, the young age, precarious living condition and lack of financial support would be constituting a risk factor increasing malaria infection.

The prevalence of placental malarial was found higher in paucigestates, and who started their intermittent preventive treatment in the second trimester of their pregnancy. Probably due to the late start of the intermittent preventive 
treatment with Sulfadoxine/Pyriméthamine different from World Health Organization's recommendation of the start of the intermittent preventive treatment (IPT) at the end of the 28 weeks of pregnancy.

Indeed, malaria prevalence is higher in the first and second trimesters of pregnancy and decreases in third trimester to reach the rate before childbirth. This would explain the high placental malaria infection prevalence in pregnant women starting their intermittent preventive treatment in the second trimester. Essibenet al. (2016) reported the same results in Cameroun.Sulfadoxine/Pyrimethamine administration was not supervised and more than $50 \%$ of the women slept regularly under untreated mosquito net (Essibenet al., 2016).

Placenta malaria prevalence was higher in pregnant women who were not talking intermittent preventive treatment unattended by a health professional and those who had no side effects after taking intermittent preventive treatment. The difference was not statically significant $(\mathrm{P}=0.2198)$. Mosquito net impregnated with repellents reduces noctural mosquito bites, thus limiting Plasmodium infestation. According to WHO, women should be encouraged to use insecticide-treatment mosquito nets throughout their pregnancy because Sulfadoxine/Pyrimethamine intermittent preventive treatment would not replace Long Lasting Insecticide Nets (LLINs).

The management strategies adopted for malaria preventive in pregnancy are the use of the LLINs, Intermittent preventive treatment of malaria in pregnancy using sulfadoxine-pyrimethamine (IPTp-SP) and adequate cases management thanks to rapid malaria treatment in pregnant women. The value of this work lies in the identification of factors that may have an influence on placental malaria infection.

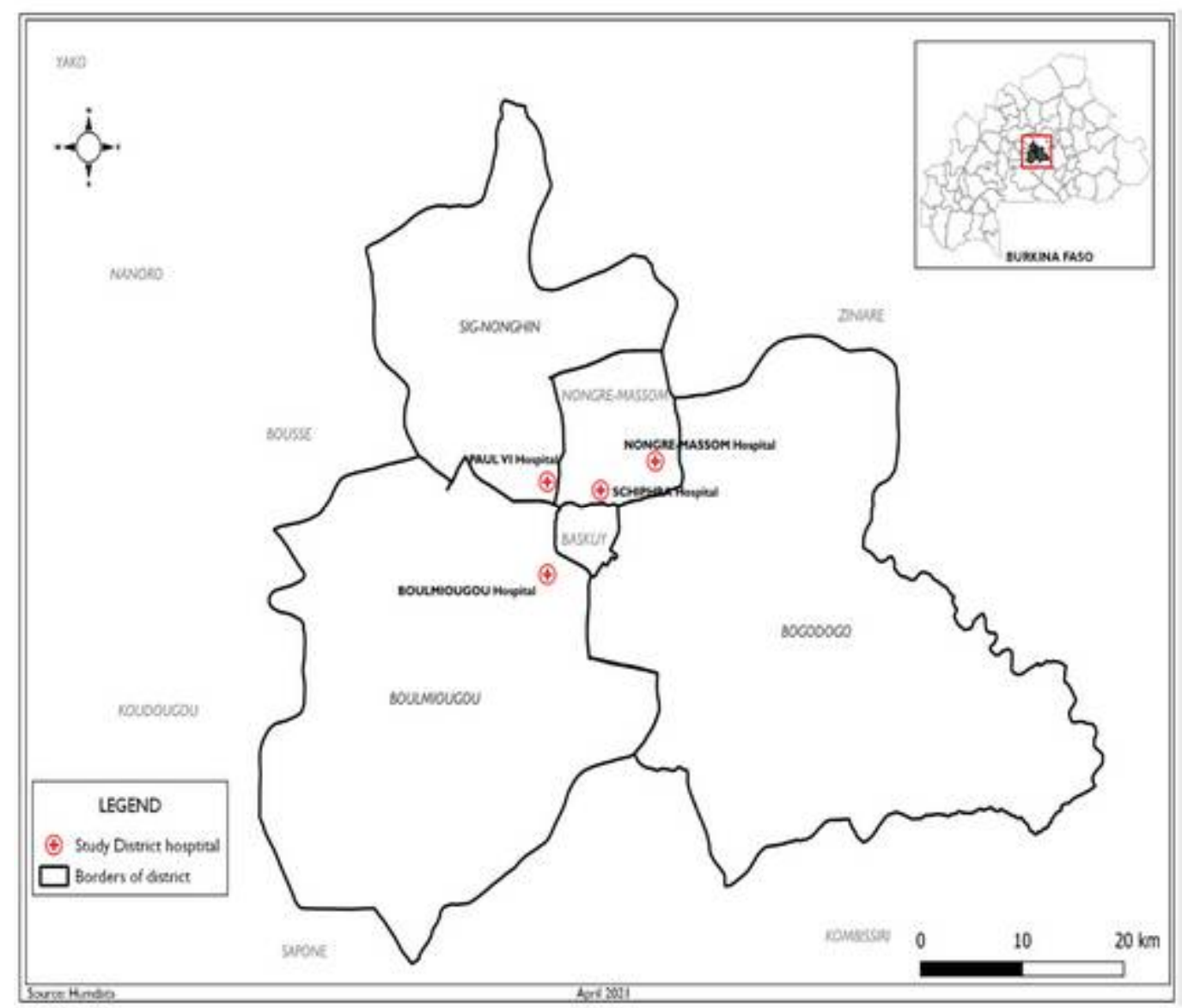

Figure 1:- Map of the study areas and selected sites. 


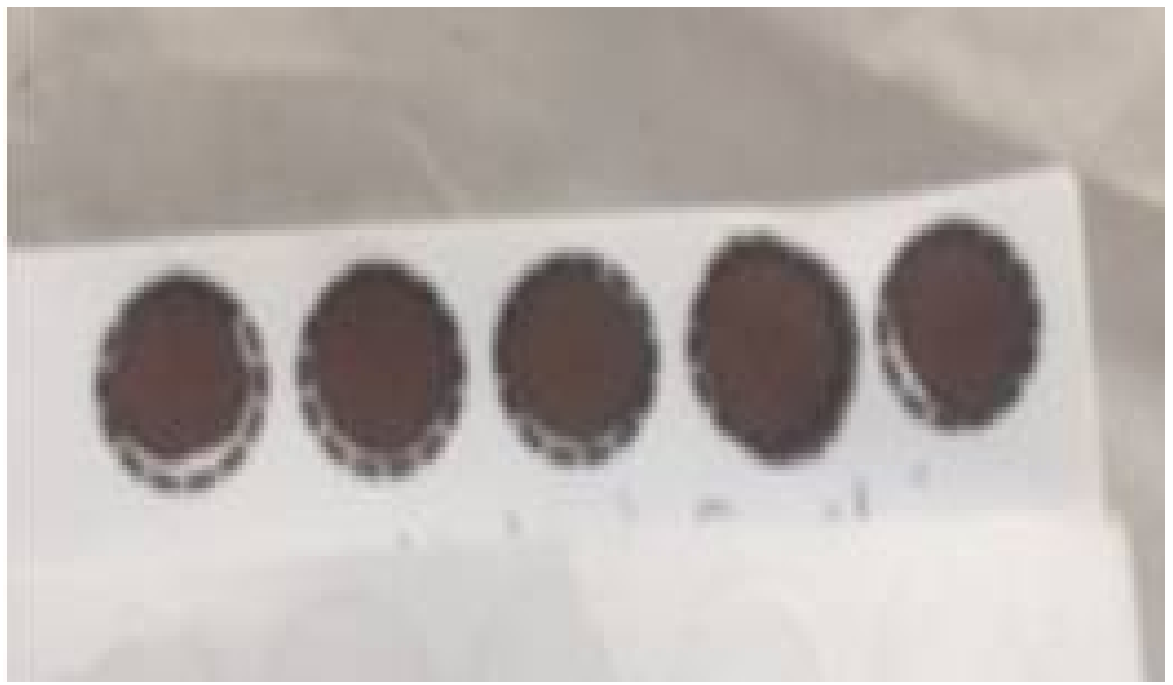

Figure 2:- Blood confetti for molecular analyses.

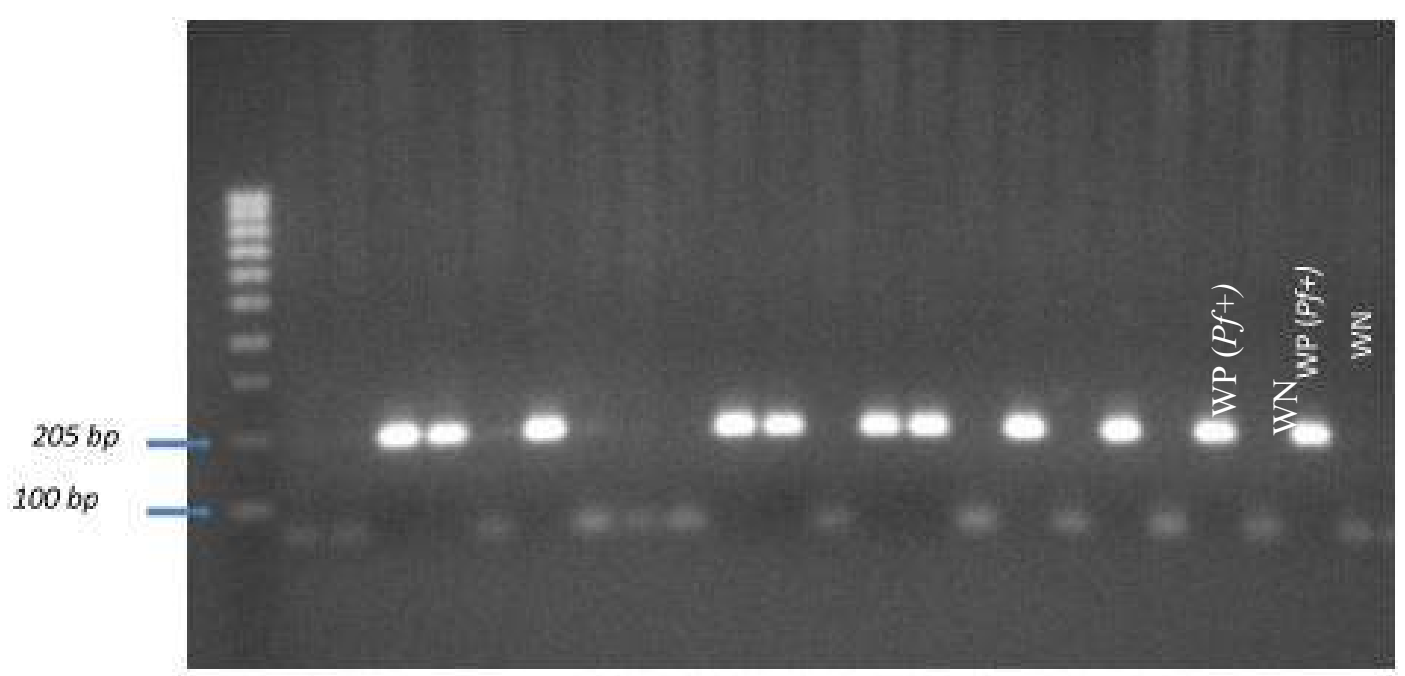

WP : positive witness $(P f+)$ of Plasmodium falciparum $W N$ : negative witness 100 bp : standard molecular weigth marker $205 \mathrm{~Pb}:$ P. falciparum diagnastic strip:

Figure 3:- bands revealed after gel migration read with UV rays

Table 1:- Identified risk factors associated with placental malaria infection.

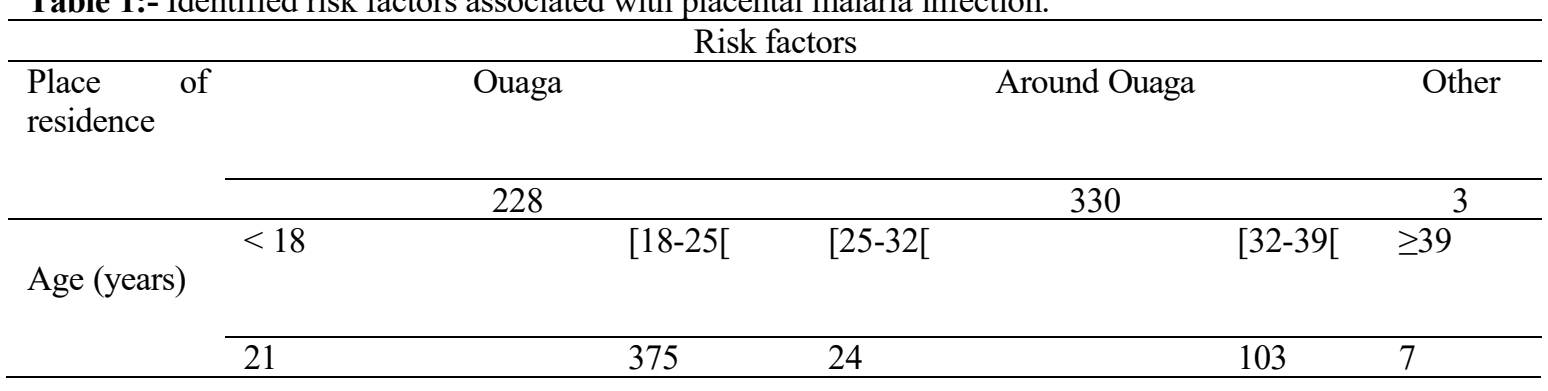




\begin{tabular}{|c|c|c|c|c|c|c|c|}
\hline \multicolumn{8}{|c|}{ Risk factors } \\
\hline \multirow[t]{2}{*}{ Profession } & $\begin{array}{l}\text { No } \\
\text { occupation }\end{array}$ & $\begin{array}{l}\text { Salaried } \\
\text { agent }\end{array}$ & Shopping & Agriculture & Breeding & Worker & Student \\
\hline & 242 & 106 & 102 & 1 & 1 & 19 & 59 \\
\hline \multirow{2}{*}{$\begin{array}{l}\text { Secondary } \\
\text { effects }\end{array}$} & No & $\begin{array}{l}\text { General } \\
\text { tired }\end{array}$ & Nausea & fear of heights & & Vomitti & \\
\hline & 412 & 53 & 15 & 4 & & 27 & \\
\hline \multirow{2}{*}{ Parity } & Primigravidae & & & Paucigravidae & & Multigra & dae \\
\hline & 182 & & & 257 & & 59 & \\
\hline \multirow{2}{*}{ Gesture } & Primigests & & & Paucigests & & Multige & \\
\hline & 163 & & & 260 & & 112 & \\
\hline \multirow[t]{2}{*}{ ANC place } & CSPS & & $\begin{array}{l}\text { Private } \\
\text { clinic }\end{array}$ & CMA & & $\mathrm{CHR}$ & Other \\
\hline & 316 & & 108 & 100 & & 5 & 2 \\
\hline \multirow[t]{2}{*}{ ANC Agent } & Gynecologist & & & Midwife & & & Other \\
\hline & 57 & & & 472 & & & 2 \\
\hline \multirow{2}{*}{ Use of LLIN } & & Yes & & & No & & \\
\hline & & 478 & & & 53 & & \\
\hline \multirow{2}{*}{ Start of IPT } & $1^{\text {er }}$ trimester & & & $2^{\text {nd }}$ trimester & & 3eme tri & ester \\
\hline & 70 & & & 430 & & 18 & \\
\hline \multirow{2}{*}{$\begin{array}{l}\text { Supervised } \\
\text { IPT }\end{array}$} & Yes & & & No & & & \\
\hline & 54 & & & 475 & & & \\
\hline
\end{tabular}

Table 2:- The influence of age, place of residence, occupation, number of pregnancies and parity on placental malaria infection.

\begin{tabular}{|c|c|c|c|c|}
\hline & \multicolumn{4}{|c|}{ PCR results } \\
\hline & & Negative & Positive & $p$ value \\
\hline Age (years) & $\begin{array}{l}<18 \text { years } \\
{[18-25[} \\
{[25-32[} \\
{[32-39[} \\
\geq 39 \text { years }\end{array}$ & $\begin{array}{c}20 \\
343 \\
24 \\
96 \\
8\end{array}$ & $\begin{array}{l}1 \\
32 \\
0 \\
7 \\
0\end{array}$ & $p=0,6298$ \\
\hline Place of residence & $\begin{array}{l}\text { Around ouaga } \\
\text { Ouaga } \\
\text { other }\end{array}$ & $\begin{array}{r}20 \\
287 \\
3 \\
\end{array}$ & $\begin{array}{l}27 \\
13 \\
0 \\
\end{array}$ & $P=0.0046$ \\
\hline Profession & No occupation & 221 & 21 & \\
\hline
\end{tabular}




\begin{tabular}{|c|c|c|c|c|}
\hline & \multicolumn{4}{|c|}{ PCR results } \\
\hline & & Negative & Positive & p value \\
\hline & salaried agent & 103 & 3 & \\
\hline & Schopping & 95 & 7 & \\
\hline & Agriculture & 0 & 1 & \\
\hline & Breeding & 1 & 0 & $P=0.0186$ \\
\hline & Worker & 16 & 3 & \\
\hline & Student & 54 & 5 & \\
\hline & Other & 1 & 0 & \\
\hline \multirow{3}{*}{ Number of gestures } & Primigeste & 151 & 12 & \\
\hline & Paucigeste & 238 & 22 & $P=0.6266$ \\
\hline & Multigeste & 106 & 6 & \\
\hline \multirow{3}{*}{ Number of parity } & Primipare & 170 & 13 & \\
\hline & Paucipare & 234 & 23 & $P=0.5424$ \\
\hline & Multipare & 87 & 4 & \\
\hline
\end{tabular}

Table 3:- Influence of the location of the Prenatal Consultation (ANC), the qualification of the ANC agent on placental malaria infection.

\begin{tabular}{|c|c|c|c|c|}
\hline & \multicolumn{4}{|c|}{ PCR results } \\
\hline & & Negative & Positive & $p$ value \\
\hline Place of prenatal consultation & $\begin{array}{l}\text { SPHC } \\
\text { CMA } \\
\text { Clinical } \\
\text { RHC } \\
\text { Other }\end{array}$ & $\begin{array}{c}290 \\
103 \\
91 \\
50 \\
2\end{array}$ & $\begin{array}{l}26 \\
5 \\
9 \\
0 \\
0\end{array}$ & $p=0.6617$ \\
\hline Prenatal consultation agent & $\begin{array}{l}\text { Gynecologist } \\
\text { Midwife } \\
\text { Other }\end{array}$ & $\begin{array}{r}56 \\
434 \\
1\end{array}$ & $\begin{array}{l}1 \\
38 \\
1\end{array}$ & $p=0.0174$ \\
\hline
\end{tabular}

Table 4:- Influence of the use of long-acting insectitice-treated mostiquo net, side effects, supervised IPT, on placental malaria infection.

\begin{tabular}{|c|c|c|c|c|}
\hline & \multicolumn{4}{|c|}{ PCR results } \\
\hline & & Negative & Positive & $p$ value \\
\hline \multirow{2}{*}{ Use of LLIN } & Yes & 441 & 37 & \multirow[b]{2}{*}{$p=0.5862$} \\
\hline & No & 5 & 3 & \\
\hline \multirow{3}{*}{ Start TPI } & Trimester 1 & 67 & 3 & \multirow{3}{*}{$p=0.2305$} \\
\hline & Trimester 2 & 396 & 34 & \\
\hline & Trimester 3 & 15 & 3 & \\
\hline \multirow{2}{*}{ TPI supervised } & Yes & 52 & 2 & \multirow[b]{2}{*}{$p=0.4847$} \\
\hline & No & 437 & 38 & \\
\hline \multirow{5}{*}{ Secondary effects } & No & 377 & 35 & \multirow{5}{*}{$p=0.2198$} \\
\hline & general fatigue & 52 & 1 & \\
\hline & Nausea & 15 & 0 & \\
\hline & fear of heights & 4 & 0 & \\
\hline & Vomiting & 27 & 1 & \\
\hline
\end{tabular}

\section{Conclusion:-}


The observed prevalence of placental parasitaemia at delivery suggest that malaria remains one of the main concerns during pregnancy. As malaria in pregnancy is responsible for several complications so emphasis should focus on communication for change of behaviour of pregnant women and also of health professionals. Our study allowed to determine placental malaria prevention and risks factors associated with placental malaria infection.

\section{Acknowledgements:-}

We express our gratitude to the pregnant women for their kind participation and cooperation. We also thank the midwifes and the health administration staff at the study sites for their kind collaboration. Thanks, are also extended to Dr OUEDRAOGO Sambo who helped in Statistical analysis. We thank West African Research Association who funded the study.

\section{References:-}

1- World Health Organization (WHO). Malaria. Who fact sheets.2021. Available from: https://www.who.int/news-room/fact-sheets/detail/malaria [accessed 10/04/2021].

2- Tegegne B, Getie S, Pillai DR. Performance of loop-mediatedisothermal amplification (LAMP) for the diagnosis of malaria among malaria suspected pregnant women in Northwest Ethiopia. Malaria journal. $2017 ; 1-7$.

3- Kanbanywanyi AM, MacArthur JR, Stolk WA, Habbema DFJ, Mshinda H, Bloland PB, Abdulla S, Kachur PS. Malaria in pregnant women in an area with sustained high coverage of insesticide-treated bed nets. Malaria journal. $2008 ; 7: 1-7$.

4- Feleke DG, Adamu A, Gebreweld A, Tesfaye M, Demissis W, Genet Molla G. Asymptomatic malaria infection among pregnant women attending antenatal care in malaria endemic areas of North-Shoa, Ethiopia: a cross-sectional study. Malaria Journal.2020; $19: 1-6$.

5- World Health Organisation (WHO). World malaria report. Geneva: World Health Organization; 2019. Licence: CC BY-NC-SA 3.0 IGO. Available from: https://www.who.int/publications/i/item/9789241565721 [accessed 12/03/2021].

6- Cissé M, Awandare GA, Soulama A, Tinto A, Hayette MP, Guiguemdé RT.Recent uptake of intermittent preventive treatment during pregnancy with sulfadoxine-pyrimethamine is associated with increased prevalence of Pfdhfr mutation in Bobo-Dioulasso, Burkina Faso. Malaria journal. 2017, 16: 1-8.

7- Cisse M, Sangare I, Lougue G,Bamba S, Bayane D, Guiguemde RT.Prevalence and risk factors for Plasmodium falciparum malaria in pregnant women attending antenatal clinic in Bobo-Dioulasso (Burkina Faso). BMC Infectious Diseases.2014, 14: 1-7.

8- Tiono AB, Ouedraogo A, Bougouma EC, Diarra A, Konaté AT, Nébié I, Sirima SB . Placental malaria and low birth weight in pregnant women living in a rural area of Burkina Faso following the use of three preventive treatment regimens. Malaria Journal. 2009, 8: 224-10.1186/1475-2875-8-224.

9- Elime FA, Nkenyi NR, Ako-Egbe L, Njunda A, Nsagha D. Malaria in pregnancy: prevalence and risk ractors in the Mamfe health district, Cameroon. Journal of Advances in Medicine and Medical Research.2019; 30:1-11. doi: 10.9734/jammr/2019/v30i130161

10- Ouedraogo CMR, Nebié G, Sawadogo L, Ouedraogo A, LankouandéJ.Study of factors favouring the occurrence of Plasmodium falciparum in pregnant women in the health district of Bogodogo. J GynecolObstet Biol Reprod (Paris). 2011 ; 40:529-34. doi: 10.1016/j.jgyn.2011.03.005

11- Organisation Mondiale de la santé. Diagnostique microscopique du paludisme : manuel d'assurance qualitéVer 2 World Health Organisation, 2020 [cited 2020 Aug 24], http://www.who.into/malaria/publication/atoz/97892415493994/fr/.

12- Valente B, Compos PA, Rosario VE do, Varandqs L, Silveira H. Prevalence and risk factors of Plasmodium falciparum infections in pregnant women of Luanda, Angola. Tropical Medecine and International Health. 2011. 16 ;1206-1214.

13- Ouédraogo A,Tiono AB,Diarra A, Bougouma ECC, Nébié I,Konaté AT,Sirima SB.Transplacental Transmission of Plasmodiumfalciparumin a Highly Malaria Endemic Area of Burkina Faso. Journal of Tropical Medecine. 2012. 84 ;3 pp. 386-389.

14- Omer SA, Idress H, Adam I, Abdelrahim M, Noureldein AN, Abdelrazig AM, Elhassan MO, Sulaiman SM. Placental malaria and its effect on pregnancy outcomes in Sudanese women from Blue Nile State. Malaria Journal. 2017.16: 374 
15- Stephens KJ, Ofori FM, Quakyi AI, Mark Lee Wilson LM, Akanmori DB. Prevalence of peripheral blood parasitaemia, anaemia and low birthweight among pregnant women in a suburban area in coastal Ghana. Pan African Medical Journal. 2014.17 ; 1-4.

16- Essiben F, Foumane P, Tsafack de Nguefack MA, EkoEko F, Njotang PN, Enow RM, Mboudou ET. Facteurs prédictifs de l'échec du Traitement Préventif Intermittent du paludisme à la sulfadoxine pyriméthamine (TPIp-SP) dans une population de femmes enceintes à Yaoundé. Pan Afr Med J. 2016 23:152. doi : 10.11604/pamj.2016.23.152.7936.

17- Crompton PD, Pierce SK, Miller LH, 2010. Advances and challenges in malaria vaccine development. The Journal of Clinical Investigation. $2010.120 ; 12: 24-39$.

18- Organisation Mondiale de la Santé : traitement préventif intermittent (TPI) pour les femmes enceintes. OMS 2013.

19- Nagalo K, Dao F, Minodier P, Sawadogo O, SanonH,Tall FH, DiarraYé. 2014 : Congénital malaria Plasmodium falciparum disease : epidémiologic , clinic, biological , thérapeutic and pronostic in Ouagadougou, Burkina Faso.The Pan African Medical Journal - ISSN. 2014 ; 1937-8688.

20- Maubert B, Fievet N, Tami G, Boudin C et Deloron P. Cytoadherence of Plasmodium falciparum -infected erytrocytes in the human placenta. Parasite immunology. 2000. 22 ;4:191-199.

21- Organisation Mondiale de la Santé. World malaria report 2015. Genève: WHO.

22- Roll Back Malaria et Programme des Nations Unies pour le Développement (PNUD) (2013). multisectoral action framework for the fight against malaria. Genève : RBM et PNUD. 2013

23- Ministère de la Santé : Nationalguideline for management of malaria in health facilities in Burkina Faso. 2014. 31 pages.

24- Ministère de la Santé: strategic plan to fight against malaria 2011-2015. Ouagadougou, Burkina Faso. National malaria control program. 2011.

25- Kurtis JD, Higashi A, Wu HW, Gundogan F, McDonald EA, Sharma S, PondTor S, Jarilla B, Sagliba MJ, Gonzal 548 A, Olveda R, Acosta L, Friedman JF. Maternal Schistosomiasis japonica is associated with maternal, 549 placental, and fetal inflammation. Infection and immunity. 2011. 79:1254-1261. 